\title{
Concerns, Positive Changes, and Suggestions for Psychological Support during COVID-19: A Thematic Analysis
}

\author{
Meta Lavrič1,2, Vanja Gomboc ${ }^{1,2}$, Nina Krohne ${ }^{1,2}$, Tina Podlogar ${ }^{1,2}$, \\ Vita Poštuvan"1,2, Nuša Zadravec Šedivy ${ }^{1,2}$, Diego de Leo ${ }^{1,2}$ \\ ${ }^{1}$ Slovene Centre for Suicide Research, Andrej Marušič Institute, University of Primorska, Koper, Slovenia \\ ${ }^{2}$ Department of Psychology, Faculty of Mathematics, Natural Sciences and Information Technologies, University of Primorska, \\ Koper, Slovenia \\ Email: meta.lavric@famnit.upr.si
}

How to cite this paper: Lavrič, M., Gomboc, V., Krohne, N., Podlogarm T., Poštuvan, V., Šedivy, N. Z., \& de Leo, D. (2020). Concerns, Positive Changes, and Suggestions for Psychological Support during COVID-19: A Thematic Analysis. Sociology Mind, 10, 187-199.

https://doi.org/10.4236/sm.2020.104012

Received: July 27, 2020

Accepted: September 27, 2020

Published: September 30, 2020

Copyright $\odot 2020$ by author(s) and Scientific Research Publishing Inc. This work is licensed under the Creative Commons Attribution International License (CC BY 4.0).

http://creativecommons.org/licenses/by/4.0/

(c) $\underset{\mathrm{BV}}{\mathrm{BV}}$ Open Access

\begin{abstract}
Background: On 12 March 2020, Slovenia formally declared the presence of a pandemic of COVID-19 disease, followed by measures to stop the spread of the virus. Scope: The aim of this study was to explore how people experienced the progress of events related to the COVID-19 epidemic. Method: We conducted a general adult population survey by an online questionnaire that included-among others-three open-ended questions. Thematic analysis was applied for each question separately to identify key patterns in the data. Results: The first topic (questions about the epidemic) resulted in four core themes: concerns about the disease, concerns about the future, concerns about measures, and concerns about well-being and daily life. The second topic (positive changes during the epidemic) resulted in three core themes: changes in oneself, changes in close relationships, and changes in the environment and society. Lastly, the third topic (requests for psychological support during the epidemic) resulted in three core themes: direct help and support, information and awareness raising, and media activity. Conclusion: Overall, the themes that emerged from our study provide information that can help in understanding how people perceive the influence on their mental health and well-being of the negative and (some) positive effects of the COVID-19 epidemic. This may be helpful in the general preparedness to a feared second wave of the pandemic.
\end{abstract}

\section{Keywords}

COVID-19 Epidemic, Concerns, Positive Changes, Psychological Support, Well-Being 


\section{Introduction}

On 30 January 2020, the World Health Organization (WHO) declared the emergence of the novel coronavirus as a public health emergency of international concern. On 11 February 2020, the infection deriving from this novel coronavirus was officially named as Corona Virus Disease 2019 (COVID-19), and, on 11 March 2020, WHO conceded the status of pandemic to it (WHO, 2020). On 12 March 2020, Slovenia declared an epidemic of COVID-19, followed by measures to stop the spread of the virus (Government of the Republic of Slovenia, 2020a). The start of the epidemic was marked by anxiety-related behaviors in the general population, such as extensive shopping for food, and shortage of masks and antiseptics in drug stores. Slovenia is a neighboring country of Italy, which has been one of the countries worst hit by COVID-19, with around $80 \%$ of cases registered in the north of the country (Michelozzi et al., 2020), which is the border of Slovenia. Nonetheless, the spread of the coronavirus was quickly slowing down in Slovenia, so the government could cancel the formal status of epidemic on 15 May. By that date, there were 1465 positive cases formally detected, and 103 deaths related to the virus (Government of the Republic of Slovenia, 2020b). However, despite the official end of the epidemic danger, the risk of spread still exists, so protective measures continue to be in place.

Considering that these measures affect individuals' daily lives, they may also affect their well-being (Sani et al., 2020). For example, in a review about psychological impact of quarantine, Brooks et al. (2020) reported negative psychological effects including post-traumatic stress symptoms, confusion, and anger. Stressors included longer quarantine duration, infection fears, frustration, boredom, inadequate supplies, inadequate information, financial loss, and stigma (Brooks et al., 2020; Mak et al., 2010). Furthermore, outbreaks of infectious disease can result in widespread fear, anxiety (Talidong \& Toquero, 2020; Baloran, 2020; Jungmann \& Witthoft, 2020) and a variety of psychological problems (Polizzi et al., 2020; Wang et al., 2020; such as posttraumatic stress symptoms (Liu et al., 2020) and suicidal behavior (Pruitt et al., 2020).

The SARS-CoV-2 (responsible for the pandemic of COVID-19) triggered the biggest economic meltdown in a century, with stock prices dropping in various parts of the world (Shigemura et al., 2020). The results of a survey done by Eurofound (2020) show that almost $40 \%$ of people in Europe reported their financial situation to be worse than before the pandemic. This leads to fears of economic hardship, stress and feelings of helplessness and hopelessness (Polizzi et al., 2020; Park et al., 2020).

Sritharan \& Sritharan (2020) emphasize that the COVID-19 pandemic is expected to continue for the coming months, with the possibility of multiple waves. Given that it is already evident that the psychological effects of the pandemic are pervasive and could affect mental health of people (Holmes et al., 2020), it is imperative to understand the magnitude of mental health issues that may arise during and after this public health crisis. 
However, while psychological research has largely focused on negative consequences of COVID-19 on health and quality of life of people, some scholars (Nelson, 2020; Szabo et al., 2020) have also noticed some positive effects of the coronavirus pandemic, such as innovative communication (Karampampas, 2020; Kraus et al., 2020) and feelings of improved social connectedness (Johnson et al., 2020). Positive emotions and good mood have important roles in coping processes to distressing situations (Folkman, 2008; Erikson \& Feldstein, 2007; Restubog et al., 2020). Nevertheless, these have been relatively neglected in research studying stress coping strategies during outbreaks (Yıldırım et al., 2020).

In response to the new coronavirus outbreak, implementation of psychological support for health workers has been developed and promoted (Geoffroy et al., 2020; Leszcz et al., 2020; Cole et al., 2020). However, research shows (Makwana, 2019) that in times of crisis, everyone, not just health workers, is more likely to develop mental health problems. For this reason, it is important to develop guidelines on how to implement psychological support for the general public. For example, research on chronic patients (Ciacci \& Siniscalchi, 2020) has shown that new technologies can help to support patients who are in need of psychological support. These findings may be transferable to general public.

While an emerging body of research has shown negative effects of the COVID-19 pandemic on people's well-being, research into the overall perception of the events surrounding the pandemic has been largely neglected. It is crucial to understand how people perceive both the negative and positive consequences of the COVID-19 pandemic in order to increase the level of preparedness in the case of a second or multiple waves of the virus. It is also important to provide people with appropriate psychological support in times of crisis, such as a pandemic.

The aim of this study was to explore how individuals experienced the progress of events concerning the epidemic, focusing on their concerns, possible positive changes and wishes for psychological support during the epidemic.

\section{Method}

\subsection{Participants}

Participants to the survey were 207 adult people, aged between 19 to 75 years old $(M=32.96, S D=11.38)$; of those, $175(84.5 \%)$ were women. Detailed sample characteristics can be seen in Table 1 .

\subsection{Measures}

We conducted a survey through an online questionnaire. Our study was conducted during the peak of the epidemic in Slovenia, when all containment measures were in force (social distancing, lockdown of municipalities, closure of kindergartens and schools, closure of public transport, etc.). The questionnaire included items about demographic variables (gender, age, education, personal 
Table 1. Sociodemographic characteristics of participants.

\begin{tabular}{|c|c|c|}
\hline & $n$ & $\%$ \\
\hline \multicolumn{3}{|l|}{ Age } \\
\hline $19-29$ & 100 & 48.3 \\
\hline $30-44$ & 72 & 34.8 \\
\hline $45-64$ & 33 & 15.9 \\
\hline $65-75$ & 2 & 1 \\
\hline \multicolumn{3}{|l|}{ Education } \\
\hline Primary school & 4 & 1.9 \\
\hline High school & 57 & 27.5 \\
\hline Bachelor's degree & 34 & 16.4 \\
\hline Master's degree & 93 & 44.9 \\
\hline Master of science & 8 & 3.9 \\
\hline Doctor of science & 9 & 4.3 \\
\hline \multicolumn{3}{|l|}{ Type of settlement } \\
\hline Urban & 128 & 61.8 \\
\hline Rural & 77 & 37.2 \\
\hline \multicolumn{3}{|l|}{ Employment status } \\
\hline Student & 67 & 32.4 \\
\hline Employed & 117 & 56.5 \\
\hline Unemployed & 13 & 6.3 \\
\hline Retired & 4 & 1.9 \\
\hline \multicolumn{3}{|c|}{ Personal income (per month) } \\
\hline Less than $550 €$ & 68 & 32.9 \\
\hline From $550 €$ to $1100 €$ & 63 & 30.4 \\
\hline From $1100 €$ to $2200 €$ & 69 & 33.3 \\
\hline More than $2200 €$ & 5 & 2.4 \\
\hline \multicolumn{3}{|c|}{ Parenthood: number of school-age or younger children } \\
\hline None & 139 & 67.1 \\
\hline One & 34 & 16.4 \\
\hline Two or more & 30 & 14.5 \\
\hline
\end{tabular}

income, type of settlement, number of school-age or younger children, and employment status) and three open-ended questions: 1) What concerns you most about the epidemic? 2) Did you notice any positive changes in yourself, your loved ones or in the surroundings during the epidemic? If so, what type of changes? 3) What do you miss or would you like to obtain from the psychology profession in connection with mental health care during the epidemic? 


\subsection{Procedure}

This study obtained data from research "Exploring the link between the COVID19 epidemic and mental health aspects (adults) under the research programme Alive? Alive!" conducted in Slovenia between 26 March and 7 April 2020. The Research Ethics Commission of the UP Famnit Department of Psychology judged that the research complied with the principles of research ethics (application number 2020-05).

Online recruitment was realised through social media (Facebook) and through the website of an ongoing project of the Slovene Centre for Suicide Research (http://zivziv.si/). Initially, descriptive analyses were performed to examine sample characteristics, using SPSS version 26 . This was followed by thematic analysis, that was applied for each question separately, using the six-phase framework to identify key patterns in the data (Braun \& Clarke, 2006; Clarke \& Braun, 2017): 1) familiarizing with the data; 2) generating initial codes; 3) searching for themes; 4) reviewing of the themes; 5) defining and naming of themes; and, 6) reporting the findings.

\section{Results}

The thematic analysis was conducted separately for each question, so that we obtained separate results for the topic of each question: 1) concerns about the epidemic; 2) positive changes during the epidemic; and, 3) wishes for psychological support during the epidemic. The themes for each topic and the internal connections between the themes are shown in Figure 1.

As depicted in Figure 1, all themes within a topic are interconnected and related to each other. However, the relationships between the topics are not as strong. Although they are all part of a broader perception of events surrounding the COVID-19 pandemic, the strongest connection is between Topic 1 (concerns about the epidemic) and Topic 3 (wishes for psychological support), in the sense

\begin{tabular}{|l|l|l|}
\hline Topic 1: Concerns & Topic 2: Positive changes & Topic 3: Psychological support \\
\hline Chemes: \\
Concerns about the measures \\
Concerns about \\
Chell-being and daily life
\end{tabular}

Figure 1. Connections between the themes. 
that the themes of Topic 1 cause the themes of Topic 3 .

\subsection{Concerns about the Epidemic}

The first topic (participants' concerns about the epidemic) led to four core themes: concerns about the disease, concerns about the future, concerns about the measures, and concerns about well-being and daily life.

Example of a quote from the first topic: "I am most concerned about my own health because I belong to the risk group. Then I worry about the health of my parents, who also belong to the risk group. I am also worried about the situation we will find ourselves in when the health crisis is solved and our world is economically ruined and needs to be rebuilt?'.

\subsubsection{Theme 1: Concerns about the Disease}

The participants reported fears of being infected or becoming infected and not knowing about it due to lack of symptoms. As a result, they were afraid of infecting their loved ones and others. They were also afraid of the disease itself, especially the consequences of the disease for their long-term well-being and health. They worried about who would take care of their children if they became ill. Dying because of COVID-19 was also a reported concern.

Participants reported concerns that family members and loved ones would fall ill, especially older relatives (who belonged to the group at risk). Participants feared that their elderly or chronically-ill close relatives would die if infected.

They also reported fears of a massive spread of infection due to failure of protective measures, which would lead to overburdening the health care system. Consequently, they feared that such a situation would lead to mass deaths. Finally, they reported concern about the spread of panic among people.

\subsubsection{Theme 2: Concerns about the Future}

With regards to the future, participants reported mainly on the unpredictability of it-they were worried about what the future would look like, what the new normality would look like. They feared unpredictable social and political consequences, but also possible changes to the environment.

Another concern was the duration of the epidemic; they feared that the long duration of the epidemic and the emergency measures would lead to serious consequences for their way of living. They expressed concern about when they would be able to return to normal life, and when they could see their loved ones and socialize as before.

\subsubsection{Theme 3: Concerns about the Measures}

Participants reported concerns about the impact of measures on jobs and the economy. They feared an imminent financial and economic crisis. As a result, they feared losing their job or not being able to find work and, thus, losing the possibility of a regular income. With regard to the measures taken by the government, participants expressed concern that politicians were exploiting the epidemiological situation by violating human rights. Some measures were per- 
ceived as impractical due to lack of protective equipment, while others were considered as nonsensical. Moreover, participants were concerned about other people failing to comply with containment measures and, consequently, about further spreading of the epidemic.

\subsubsection{Concerns about Well-Being and Daily Life}

Participants reported concerns about own well-being and mental health and that of other people. They also expressed some concerns about pregnancy or childbirth at the time of the epidemic, and concerns about homeschooling of children as well as traveling to other countries.

\subsection{Positive Changes during the Epidemic}

With regards to perceiving possible positive changes in time of COVID-19, this resulted in three core themes: 1) changes in oneself; 2) changes in close relationships; and, 3) changes in the environment and society.

Example of a quote from the second topic: "It seems to me that many people have become more relaxed in the sense that time no longer weights so heavily on them. Many have contact with their families and finally have time for each other. When I walk down the street, I notice that people are looking for eye contact and greetings, because it looks like we are really all in the same boat and feel empathy for each other. A lot of goodness has awakened in people. I notice that many people still choose to volunteer and help wherever they can. In all this chaos, many beautiful things are happening, even the planet is finally breathing a little easier, at least for a while".

\subsubsection{Theme 1: Changes in Oneself}

Participants reported getting to know themselves better, learn about priorities, values, their inner strength and happiness, the importance of loved ones in their lives and about their life experiences. They felt more grateful and less focused on materialism and consumerism.

They also reported that they found more time for themselves, which they used for regular physical exercise, new sports activities, more time in natural environments, creative activities and eating healthy food. They also reported that they were trying out various new hobbies for which they had not had time before, such as relaxation, mindfulness and yoga techniques.

They experienced a greater sense of calm, a life in the "here and now", less daily rush, less or no time to commute and fewer daily commitments. As a result, they felt more motivated for activities that they would otherwise postpone; they were more concentrated, organized and less tired at work.

\subsubsection{Theme 2: Changes in Close Relationships}

Participants reported that they felt more connected to others, that they established better relationships and also felt more empathy towards other people. There was more time for the loved ones, and the quality of time spent with the family was better. They communicated more, even if only by phone or online 
media. Keeping in good spirit was a way to connect with loved ones and at the same time a mechanism for coping with the epidemic.

\subsubsection{Theme 3: Changes in the Environment and Society}

Participants noticed less polluted air and less pollution in general, a cleaner environment and less traffic. They also noticed that, in general, people followed safety instructions, which they perceived as a major concern for society. There was a feeling of mutual solidarity, friendliness for each other and good "team" spirit: e.g. balcony concerts. Solidarity was also shown in volunteer work, e.g. helping elderly people with shopping. Society was changing due to the epidemic, and these changes included more local shopping initiatives and the development of home delivery, which was perceived as positive.

\subsection{Wishes for Psychological Support during the Epidemic}

The third topic, participants' wishes for psychological support during the COVID19, yielded three core themes: 1) direct help and support; 2) information and awareness raising; and, 3) media activity.

Example of a quote from the third topic: "I would like reassuring information, instructions on how to take care of mental health and the possibility of direct help (online, telephone) for those who need it'.

\subsubsection{Theme 1: Direct Help and Support}

Participants expressed their wishes for counseling and psychological support via telephone or video therapy. They stressed that help should be accessible and free of charge. Particular attention should be paid to older adults, sick and vulnerable people, people with mental health problems, pregnant women, people without Internet access, and victims of domestic violence.

They also wanted guidance on motivational, relaxation and coping techniques, as well as on learning mindfulness and meditation.

\subsubsection{Theme 2: Information and Awareness Raising}

Participants would like to receive educational and informational content in the form of concrete information and ideas or suggestions for mental health exercises and activities. Tips for dealing with isolation, fear, stress and feelings of helplessness would also be helpful. They would also like some practical tips on how to best co-habiting, how to maintain mental health and how to stay calm in certain situations, e.g. when shopping.

Participants expressed the need for information on the impact of the epidemic on mental health. They suggested raising awareness through webinars or online lectures.

\subsubsection{Theme 3: Media Activity}

With regard to the media activities of psychologists, participants wrote about increasing information on mental health issues and helping journalists to create appropriate content. In addition, they wished that the experts would help to 
counterbalance the media panic by publishing positive and reassuring news and by appearing in news programs on TV and in online media sites.

\subsection{Discussion}

The aim of this study was to investigate participants' concerns, the possibility of positive changes and wishes for psychological support during the epidemic using a thematic analysis framework. The resulting themes provided comprehensive theoretical framework for understanding challenges, emotional responses, coping strategies and resources that influence the adaptation of participants to the epidemic of COVID-19.

Participants reported concerns about the disease, especially that they could become infected or their relatives could fall ill. They worried about the health of their elderly or chronically-ill relatives, who belonged to the risk group. They also worried about the future and the unpredictability of the epidemic. Participants reported concerns about the impact of the containment measures on jobs and the economy. They feared a looming financial and economic crisis. These findings are in line with previous research on fears of economic distress due to the COVID-19 pandemic (Polizzi et al., 2020; Park et al., 2020). Other concerns related to containment measures included political exploitation of the epidemiological situation, unfeasibility of measures and non-compliance by other people.

We also examined possible perception of positive changes by the participants. Their reports are consistent with previous research on better and more innovative communication (Karampampas, 2020; Kraus et al., 2020) and feelings of social connection (Johnson et al., 2020). They also reported on the importance of humor as a way to connect with loved ones and as a mechanism for coping with an epidemic, which is consistent with previous research (Folkman, 2008; Erikson \& Feldstein, 2007; Restubog et al., 2020). Furthermore, participants emphasized the presence of positive changes in themselves, especially the learning of priorities, values and their inner strengths. Despite the reported concerns, they experienced a greater sense of calm and gratitude.

Finally, we meant to find out what participants wanted in terms of psychological support during the COVID-19 pandemic. Holmes et al. (2020) stressed the importance of understanding the mental health problems that arise during and after the COVID-19 crisis, so it is also important to understand how we can prevent or mitigate these problems. Participants expressed the desire for counseling and direct psychological support, which should be easily accessible and free of charge. In Slovenia, telephone lines have been opened to offer psychological help to everyone free of charge, and many therapists offered their services free of charge via video calls. Participants also emphasized that special attention should be paid to risk groups and persons suffering from domestic violence. They also wished for more educational and informative content, guidance on coping techniques and concrete advice on how to maintain mental health. They 
also expressed the importance of media activity, which should be more informative, reassuring and positive. This reflects the concern expressed about the unpredictability of the future and the fear of an economic crisis. Our findings suggest that psychologists should be more involved in media coverage, as this would provide an opportunity to reach a wider public and offer them educational, helpful and reassuring information on the mental health aspect of the COVID-19 epidemic.

\section{Conclusion}

Strengths of this study were that participants were detailed in their responses and shared a large amount of information. The anonymity of the process enabled this level of disclosure. This study also broadened the participant pool by accessing participants from a range of ages. However, there were limitations to the study. The sampling strategy was not random and this may therefore lead to bias, as it was impossible for people without access to the Internet to participate in the study. Second, most individuals of our sample were females and younger people, and therefore findings may not transfer to males and older people. The study is based on a qualitative analysis of the participants' subjective experiences. Therefore, one of the limitations is that the results of the study cannot be generalized due to the chosen method, the purpose of which was to understand and explain the data. Future studies will use methods allowing for data generalization and sample representativeness.

Overall, themes emerging in our study provided information that can be helpful in understanding how people perceive negative and eventually positive effects of the COVID-19 epidemic on mental health and well-being. In addition, results provided suggestions on how to organise psychological support that can be used to design and implement mental health interventions to ensure people's well-being during and after epidemics. It would be possible to prevent or mitigate their worries (e.g. by reducing fears of unpredictable future scenarios through reassurance and consistency of information), reinforce perceived positive changes (e.g. enhancing the sense of calm through the use of mindfulness and relaxation techniques), and, most importantly, address people's needs and wishes for psychological support. All these measures could be important strategies in increasing the level of preparedness in the feared case of a second or multiple waves of the virus.

\section{Acknowledgements}

This work was supported by the Slovenian Research Agency under Grant number P3-0384.

\section{Conflicts of Interest}

The authors declare no conflicts of interest regarding the publication of this paper. 


\section{References}

Baloran, E. T. (2020). Knowledge, Attitudes, Anxiety, and Coping strategies of Stufents during COVID-19 Pandemic. Journal of Loss and Trauma, 25, 635-642. https://doi.org/10.1080/15325024.2020.1769300

Braun, V., \& Clarke, V. (2006). Using Thematic Analysis in Psychology. Qualitative Research in Psychology, 3, 77-101. https://doi.org/10.1191/1478088706qp063oa

Brooks, S. K., Webster, R. K., Smith, L. E., Woodland, L., Wessely, S., Greenberg, N., \& Rubin, G. J. (2020). The Psychological Impact of Quarantine and How to Reduce It: Rapid Review of the Evidence. The Lancet, 395, 912-920. https://doi.org/10.1016/S0140-6736(20)30460-8

Ciacci, C., \& Siniscalchi, M. (2020). Tips from the Battlefront: Psychological Support of Patients with a Chronic Illness during the COVID-19 Lockdown in Four Steps. United European Gastroenterology Journal, 8, 741-742. https://doi.org/10.1177/2050640620927564

Clarke, V., \& Braun, V. (2017). Thematic Analysis. The Journal of Positive Psychology, 12, 297-298. https://doi.org/10.1080/17439760.2016.1262613

Cole, C. L., Waterman, S., Stott, J., Saunders, R., Buckman, J. E. J., Pilling, S., \& Wheatley, J. (2020). Adapting IAPT Services to Support Frontline NHS Staff during the Covid-19 Pandemic: The Homerton Covid Psychological Support (HCPS) Pathway. The Cognitive Behaviour Therapist, 13, 1-12. https://doi.org/10.1017/S1754470X20000148

Erikson, S. J., \& Feldstein, S. W. (2007). Adolescent Humor and Its Relationship to Coping, Defense Strategies, Psychological Distress, and Well-Being. Child Psychiatry and Human Development, 37, 255-271. https://doi.org/10.1007/s10578-006-0034-5

Eurofound (2020). Living, Working and COVID-19: First Findings April 2020. https://www.eurofound.europa.eu/publications/report/2020/living-working-and-covid19-first-findings-april-2020\#tab-05

Folkman, S. (2008). The Case for Positive Emotions in the Stress Process. Anxiety, Stress, and Coping, 21, 3-14. https://doi.org/10.1080/10615800701740457

Geoffroy, P. A., Le Goanvic, V., Sabbagh, O., Richoux, C., Weinstein, A., Dufayet, G., \& Lejoyeux, M. (2020). Psychological Support System for Hospital Workers during the Covid-19 Outbreak: Rapid Design and Implementation of the Covid-Psy Hotline. Frontiers in Psychiatry, 11, 511. https://doi.org/10.3389/fpsyt.2020.00511

Government of the Republic of Slovenia (2020a). Slovenia Declares Coronavirus Epidemic. https://www.gov.si/en/news/2020-03-12-slovenia-declares-coronavirus-epidemic

Government of the Republic of Slovenia (2020b). Slovenia Declares the End of COVID-19 Epidemic; No Quarantine for EU Citizens from Today. https://www.gov.si/en/news/2020-05-15-slovenia-declares-the-end-of-covid-19-epidem ic-no-quarantine-for-eu-citizens-from-today

Holmes, E. A., O’Connor, R. C., Perry, V. H., Tracey, I., Wessely, S., Arseneault, L., Ballard, C., Christensen, H., Cohen Silver, R., Everall, I., Ford, T., John, A., Kabir, T., Madan, I., Michie, S., Przybylski, A. K., Shafran, R., Sweeney, A., Worthman, C. M., Bullmore, E. et al. (2020). Multidisciplinary Research Priorities for the COVID-19 Pandemic: A Call for Action for Mental Health Science. The Lancet Psychiatry, 7, 557-560. https://doi.org/10.1016/S2215-0366(20)30168-1

Johnson, M. C., Saletti-Cuesta, L., \& Tumas, N. (2020). Emotions, Concerns and Reflections Regarding the COVID-19 Pandemic in Argentina. Ciencia \& Saude Coletiva, 25, 2447-2456. https://doi.org/10.1590/1413-81232020256.1.10472020

Jungmann, S. M., \& Witthoft, M. (2020). Health Anxiety, Cyberchondria, and Coping in 
the Current COVID-19 Pandemic: Which Factors Are Related to Coronavirus Anxiety? Journal of Anxiety Disorders, 73, Article ID: 102239. https://doi.org/10.1016/j.janxdis.2020.102239

Karampampas, P. (2020). Partying at Times of Crises and Pandemics: Solidarity, Resilience and Coping with the Measures against COVID-19. Social Anthropology, 28, 292-293. https://doi.org/10.1111/1469-8676.12887

Kraus, S., Clauss, T., Breier, M., Gast, J., Zardini, A., \& Tiberius, V. (2020). The Economics of COVID-19: Initial Empirical Evidence on How Family Firms in Five European Countries Cope with the Corona Crisis. International Journal of Entrepreneurial Behavior \& Research, 26, 1067-1092. https://doi.org/10.1108/IJEBR-04-2020-0214

Leszcz, M., Maunder, R., \& Hunter, J. (2020). Psychological Support for Health Care Workers during the COVID-19 Pandemic. Canadian Medical Association Journal, 192, E660. https://doi.org/10.1503/cmaj.75864

Liu, N., Zhang, F., Wei, C., Jia, Y., Shang, Z., Sun, L., Wu, L., Sun, Z., Zhou, Y., Wang, Y., \& Liu, W. (2020). Prevalence and Predictors of PTSS during COVID-19 Outbreak in China Hardest-Hit Areas: Gender Differences Matter. Psychiatry Research, 287, Article ID: 112921. https://doi.org/10.1016/j.psychres.2020.112921

Mak, I. W., Chu, C. M., Pan, P. C., Yiu, M. G., Ho, S. C., \& Chan, V. L. (2010). Risk Factors for Chronic Post-Traumatic Stress Disorder (PTSD) in SARS Survivors. General Hospital Psychiatry, 32, 590-598. https://doi.org/10.1016/j.genhosppsych.2010.07.007

Makwana, N. (2019). Disaster and Its Impact on Mental Health: A Narrative Review. Journal of Family Medicine and Primary Care, 8, 3090-3095.

https://doi.org/10.4103/jfmpc.jfmpc_893_19

Michelozzi, P., de’Donato, F., Scortichini, M., De Sairo, M., Noccioli, F., Rossi, P., \& Davoli, M. (2020). Mortality Impacts of the Coronavirus Disease (COVID-19) Outbreak by Sex and Age: Rapid Mortality Surveillance System, Italy, 1 February to 18 April 2020. Eurosurveillance, 25, 2-6. https://doi.org/10.2807/1560-7917.ES.2020.25.19.2000620

Nelson, B. (2020). The Positive Effects of COVID-19. British Medical Journal, 369, m1785. https://doi.org/10.1136/bmj.m1785

Park, C. L., Russell, B. S., Fendrich, M., Finkelstein-Fox, L., Hutchison, M., \& Becker, J. (2020). Americans' COVID-19 Stress, Coping, and Adherence to CDC Guidelines. Journal of General Internal Medicine, 35, 2296-2303. https://doi.org/10.1007/s11606-020-05898-9

Polizzi, C., Lynn, S. J., \& Perry, A. (2020). Stress and Coping in the Time of COVID-19: Pathways to Resilience and Recovery. Clinical Neuropsychiatry, 17, 59-62.

Pruitt, L. D., Mcintosh, L. S., \& Reger, G. (2020). Suicide Safety Planning During a Pandemic: The Implications of COVID-19 on Coping with a Crisis. Suicide and Life-Threatening Behavior, 50, 741-749. https://doi.org/10.1111/sltb.12641

Restubog, S. L. D., Ocampo, A. C. G., \& Wang, L. (2020). Taking Control amidst the Chaos: Emotion Regulation during The COVID-19 Pandemic. Journal of Vocational Behavior, 119, Article ID: 103440. https://doi.org/10.1016/j.jvb.2020.103440

Sani, G., Janiri, D., Di Nicola, M., Janiri, L., Ferretti, S., \& Chieffo, D. (2020). Mental Health during and after the COVID-19 Emergency in Italy. Psychiatry and Clinical Neurosciences, 74, 372-373. https://doi.org/10.1111/pcn.13004

Shigemura, J., Ursano, R. J., Morganstein, J. C., Kurosawa, M., \& Benedek, D. M. (2020). Public Responses to the Novel 2019 Coronavirus (2019-Ncov) in Japan: Mental Health Consequences and Target Populations. Psychiatry and Clinical Neurosciences, 74, 281. https://doi.org/10.1111/pcn.12988 
Sritharan, J., \& Sritharan, A. (2020). Emerging Mental Health Issues from the Novel Coronavirus (COVID-19) Pandemic. Journal of Health and Medical Sciences, 3, 157-162. https://doi.org/10.31014/aior.1994.03.02.109

Szabo, T. G., Richling, S., Embry, D. D., Biglan, A., \& Wilson, K. G. (2020). From Helpless to Hero: Promoting Values-Based Behavior and Positive Family Interaction in the Midst of COVID-19. Behavior Analysis in Practice, 13, 568-576.

https://doi.org/10.1007/s40617-020-00431-0

Talidong, K. J. B., \& Toquero, C. M. D. (2020). Philippine Teachers' Practices to Deal with Anxiety amid COVID-19. Journal of Loss and Trauma, 25, 573-579. https://doi.org/10.1080/15325024.2020.1759225

Wang, C., Pan, R., Wan, X., Tan, Y., Xu, L., Ho, C. S., \& Ho, R. C. (2020). Immediate Psychological Responses and Associated Factors during the Initial Stage of the 2019 Coronavirus Disease (COVID-19) Epidemic among the General Population in China. International Journal of Environmental Research and Public Health, 17, 1729. https://doi.org/10.3390/ijerph17051729

World Health Organization (WHO) (2020). Novel Coronavirus (2019-nCoV): Situation Report 22.

https://www.who.int/emergencies/diseases/novel-coronavirus-2019/situation-reports

Yıldırım, M., Akgül, Ö., \& Geçer, E. (2020). The Effect of COVID-19 Anxiety on General Health: The Role of COVID-19 Coping. https://doi.org/10.31234/osf.io/h8w9e 